\title{
Estudos curriculares: desafios teóricos e metodológicos
}

José Augusto Pacheco*

\section{Resumo}

Com fronteiras disciplinares muito permeáveis, os estudos curriculares têm enfrentado alguns desafios teóricos e metodológicos. Argumento, neste artigo, que a construção complexa da identidade e a análise de diversas abordagens, por vezes, contraditórias, dos estudos curriculares são desafios que necessitam de ser debatidos criticamente. Incluise, ainda, uma breve referência às tradições curriculares e aos desafios metodológicos centrados na pesquisa curricular, em Portugal. A leitura deste artigo torna-se, assim, fundamental para alunos de cursos de graduação e pós-graduação, bem como para professores e educadores ligados quer às questões da educação e formação, em geral, quer às questões do currículo, que inclui também uma referência à didática e à pedagogia. Palavras-chave: Estudos Curriculares. Teoria. Identidade. Pesquisa. Tradições.

\section{Introdução}

Na compreensibilidade do mundo social empírico, as ciências sociais, como campo científico (BOURDIEU, 2004), têm não só o problema da dicotomização, a partir do elemento contrastante das ciências naturais (WEBER, 1977), como também a discussão em torno da ideologia e do que se entende por "análise crítica das experiências" (POPPER, 2009, p. 65). Por isso, a abordagem de um campo de conhecimento das ciências sociais, como é o caso da educação, em geral, e dos estudos curriculares, em particular, requer a consideração de uma série de questões prévias, por exemplo: o conhecimento curricular não é de natureza puramente técnica e generalizável, a identidade daí resultante é algo em construção e a sua natureza epistemológica é interdisciplinar, de fronteiras porosas e, inclusive, indefinidas e incertas (GARCIA; MOREIRA, 2003).

Na escrita deste artigo, sustento que a identidade dos estudos curriculares é um fator simultâneo de fragilização e consolidação (PACHECO, 2011a, 2012), uma vez que têm sido questionados, ao longo das últimas décadas, por paradigmas diferentes (TYLER, 1949; PINAR, 1975; MALEWSKI, 2010a), teorias divergentes (SILVA, 2000; LEITE, 2002; PACHECO, 2006; FERNANDES, 2011; MACEDO, LOPES, 2011), politicas e práticas não consensuais (MOREIRA, 2003a; PINAR, 2007a) e pesquisas metodologicamente distintas em torno de uma realidade educacional bem complexa (PINAR, 2011).

* Professor Catedrático da Universidade do Minho.E-mail:jpacheco@ie.uminho.pt. 
São, assim, três os pontos estruturantes do artigo: 1) desafios teóricos dos estudos curriculares; 2) tradições dos estudos curriculares em Portugal; 3) desafios metodológicos dos estudos curriculares.

\section{Desafios teóricos dos estudos curriculares}

A identidade teórica, na qual se incluem a integração na educação e as fronteiras que constantemente são definidas como epistemologicamente válidas, bem como as diferentes abordagens, que contribuem para a referenciação de políticas, processos e práticas, são os dois principais desafios que os estudos curriculares enfrentam hoje. A questão da relação dos estudos curriculares com a educação, didática e pedagogia tem sido recorrente e fundamentada em argumentos que nem sempre são amplamente partilhados, mais ainda quando estão em causa territórios profissionais no âmbito das instituições de ensino superior. A partilha e a delimitação de espaços profissionais são, assim, fatores determinantes na (des) construção e na (in) visibilidade de campos de conhecimento, como se observa no interior das ciências da educação (designação já por si portadora de conflitos).

Dada a sua pluralidade identitária e a sua multirreferencialidade (BOAVIDA; AMAD0, 2008; ESTRELA, 2007; ESTRELA, 1999, 1992; CARVALHO, 1986), as ciências da educação não têm uma relação de conflitualidade epistemológica com os estudos curriculares, a não ser que se aceite como válida a asserção de que "o currículo é a peça central da actividade educacional" (BEYER; LISTON, 1996, p. 15). Tal centralidade é justificável se currículo for sinónimo de conhecimento, pois não é possível falar de projeto de formação sem a inclusão de referências relativas a um corpus de saberes e valores, social e culturalmente reconhecido como válido.

Sem ter uma referência paradigmática concreta fora das ciências da educação, pois a sua pertença às ciências sociais caracteriza-se pela itinerância epistemológica, os estudos curriculares consagram uma pluralidade de referências disciplinares, umas ligadas às orientações, outras ao processo, de acordo com a sua génese conceptual dividida entre currículo e instrução. A este respeito, Mauritz Johnson (1980, p. 18) escreve, em artigo publicado em 1967: "Não há dúvida que o currículo desempenha algum papel na orientação do ensino. Se assim o é. Deve ser visto como antecipatório e não como descrição acabada dos fatos. Currículo implica intenção".

É esta separação teórico-prática que tem conferido aos estudos curriculares a sua errância conceptual, isto é, uma identidade fragmentada entre os conceitos de currículo e de desenvolvimento curricular, como se fosse possivel reduzir os estudos curriculares às ciências do ensino ou à didática geral. Com efeito, poder-se-á dizer que a origem dos estudos curriculares, e a consequente aquisição de uma cidadania epistemológica, ocorre nos parâmetros conceptuais da didática, com uma forte ligação ao desenvolvimento curricular ou à instrução. Não é sem razão que o currículo tenha na sua origem teórica uma racionalidade técnica associada à teoria de instrução de Ralph Tyler (1949), sendo, 
frequentemente, definido como sinónimo de ensino e aprendizagem. Nesse sentido, a noção de desenvolvimento curricular, que é utilizada quer no contexto académico, quer no contexto escolar e nos textos normativos, tem sido a terminologia referenciada em Portugal para a identificação dos estudos curriculares.

De facto, trata-se de uma identidade que se afirmou com muita consistência em muitos paises europeus e que tem perdurado em Portugal, sendo reconhecivel ainda hoje no contexto académico e nos discursos políticos. Por mais entendimentos que existam sobre as componentes de desenvolvimento do currículo (GASPAR; ROLDÃO, 2007), ou 1 sobre a didática (OLIVEIRA, 2001, 2002, 2011; LIBÂNEO, 2011), ou sobre as didáticas (MARTINAND, 2007), considero que é a didática que se constitui num objeto de estudo do currículo, e não o contrário, pois currículo não é somente ensino e aprendizagem, mas também conhecimento. Dito desse modo, não há nos estudos curriculares lugar para o enunciado disjuntivo quando se aborda conceptualmente $o$ currículo e a didática. E mesmo que a designação persista nas práticas de organização curricular das instituições de ensino superior, currículo e didática constituem uma disjunção inclusiva. Assim, os estudos curriculares são "o estudo interdisciplinar da experiência educativa. Com efeito, nem todo o estudo interdisciplinar da experiência educativa é interdisciplinar. A teoria do currículo é um campo de estudo distinto, com uma história única, um presente complexo, um futuro incerto" (PINAR, 2007a, p. 18).

Por seu turno, a didática diz respeito ao processo de ensino-aprendizagem, numa construção epistemológica que foi em parte colonizada pela psicologia (AUTIO, 2006), com o predomínio de "modelos comportamentais" (PINAR, 2007a, p. 19), numa interrelação com as didáticas ligadas às ciências da especialidade ${ }^{1}$. Assim, a didática tem constituído um campo de conhecimento sobre o ensino, acentuando-se duas visões distintas que têm levantado obstáculos à interseção do currículo e do desenvolvimento curricular. Como refere Maria Teresa Estrela (2011, p. 31), "o encontro da tradição anglo-americana dos estudos curriculares com a tradição dos paises da Europa latina, fortes na investigação didática, não contribui para um esclarecimento de conceitos delimitadores dessas áreas disciplinares", o que pode tornar-se num argumento explicativo para que o núcleo duro dos estudos curriculares esteja no ensino e na aprendizagem e que currículo seja sinónimo de didática, pois é tanto o estudo dos processos e práticas pedagógicas institucionalizados, a partir de pressupostos de ordem política, social e cultural, quanto o estudo dos elementos substantivos ou nucleares do currículo (objetivos, competências, conteúdos, atividades e avaliação).

Não sendo campos contraditórios, ou dissociados, currículo e didática não têm objetos de estudo distintos, pelo que a sua interligação se faz pelas referências

Constata-se a existência de quadros bem diferentes nas instituições de ensino superior, em Portugal, para o lugar das didáticas, ora fazendo parte integrante das ciências da educação, ora estando incluídas nas ciências da especialidade. 
ao espaço da aprendizagem, correspondente, na escolarização formal, à sala de aula. Deste modo, "uma concepção integrada de currículo e pedagogia exige que o ensino seja compreendido como um processo curricular e não apenas como uma troca interpessoal" (DOYLE, 1992, p. 507), fazendo com que os estudos curriculares se construam na base da pluralidade, sem visões fragmentadas, pelo que "podem constituir a única disciplina académica dentro do campo mais alargado da educação. Muitas das ciências sociais, mais especificamente a psicologia e a sociologia, colonizaram muito o campo da educação. Somente a teoria do currículo tem a sua origem e deve a sua lealdade à experiência da educação" (PINAR, 2007a, p. 18-19).

Sendo entendido como um campo de intervenção nos problemas de educação e formação, os estudos curriculares não se limitam unicamente a uma abordagem técnica, pretensamente neutra e pautada por critérios de implementação. Como construção cultural, social, política e ideológica (GOODSON, 2001; YOUNG, 2010a; PACHECO, 2005; MOREIRA, 2003a), o currículo é, ao mesmo tempo, teoria e prática, contendo quer o campo da teorização e da discursividade - para John Goodlad e Zhixin Su (1992), aos níveis "social, institucional, instrucional e dialógico" -, quer o campo das práticas organizacionais e pedagógicas. Por conseguinte, e porque não constituem um campo dotado de paradigmas, teorias e métodos próprios, os estudos curriculares necessitam de buscar noutras "áreas científicas teorias como ponto de partida de investigação curricular" (ESTRELA, 2011, p. 32), o que acentua a sua interdisciplinaridade no interior das ciências da educação e das ciências sociais, aliás como tem sido sublinhado por vários autores portugueses (por exemplo, ROLDÃO, 1998, 199I, 2011; ALONSO, 1999; LEITE 2002; ALVES, 2004; MORGAD0, 2005; FERNANDES, 2011).

A difícil construção da identidade dos estudos curriculares advém da sua complexidade teórica, em grande parte, da diversidade existente, como reconhece Maria Teresa Estrela (2007, p. 29): "aqueles que inscrevem o currículo e as disciplinas que se organizam à sua volta na área das ciências da educação não poderão furtar-se aos problemas que a sua pertença epistemológica obriga a partilhar, as dificuldades e ambiguidades de umas reforçando as das outras e gerando ciclos viciosos difíceis de romper". E que ciclos são estes?

Embora a autora não os mencione, penso que há, pelo menos, dois ciclos específicos: um tem que ver com a cientificidade da educação e do currículo, sobretudo no que se pode entender pelo reconhecimento que têm no seio das ciências sociais e no âmbito da comunidade científica (PACHECO, 2007); outro diz respeito à qualidade da produção, sendo de admitir que, na educação, há lacunas evidentes ao nivel da produção científica e da investigação (PACHECO, 2010; ESTRELA, 2007; LIMA, 2003; NÓVOA, 2001) e que, no campo curricular, há uma "difícil separação entre ciência e ideologia, tornando-se "particularmente permeável à intrusão de ideologias políticas, como as teorias críticas documentam" (ESTRELA, 2011, p. 32). 
Há de igual modo, um ciclo mais geral, relacionado com a permeabilidade epistemológica dos estudos curriculares. Esta é uma questão em permanente debate, pois em torno das práticas, dos contextos e das teorias do currículo torna-se impossível a construção de qualquer consenso. Por isso, penso, tal como o faz Albano Estrela (1992, p. 19) para as ciências da educação, que a diversidade de abordagens não deverá significar "um obstáculo epistemológico, mas sim e apenas uma questão de ordem metodológica". Não considero, assim, e sublinhando ideias de Bernard Charlot (2007) e Maria Teresa Estrela (2011) sobre as ciências da educação, que o campo dos estudos curriculares seja epistemologicamente fraco, de fronteiras ténues e de conceitos fluidos.

A diversidade teórica dos estudos curriculares é algo que tem estado na sua afirmação como campo de estudo autónomo, reconhecendo-se a sua abrangência devido, em parte, às problemáticas que integram o seu objeto próprio e ao seu hibridismo conceptual. Apesar de serem moldados por uma tradição escolar, que incorpora uma perspetiva ateórica e técnica, em termos do seu processo de desenvolvimento, ou da sua afirmação como texto institucional, os estudos curriculares não podem ignorar a dimensão teórica, mesmo que, desde a sua génese, se reconheça que estejam confrontados com um "problema de identidade" (PAGE, 2009, p. 9), com milhares de vozes e proliferação de discursos (SNAZA, 2010; PINAR, 2010c; PINAR, REYNOLDS, SLATERRY, TAUBMAN, 1995), no seguimento da mudança do paradigma tyleriano para o paradigma da compreensão (PINAR, 1975, 2006, 2007b, 2008), e da consequente existência de uma multiplicidade discursiva, prisioneira, como escreve William Pinar (2010a, p. 528), de "políticos malévolos" e de "académicos oportunistas".

Tal crise identitária pode ser entendida não como uma fragilidade, mas como uma questão positiva na afirmação epistemológica dos estudos curriculares, mormente quando se reconhece que a pós-reconceptualização, surgida com as ideias pós-estruturalistas, pós-modernistas e pós-coloniais, é caraterizada, entre outros aspetos, pelos espaços híbridos, pelas leituras de diferença, pelas perspetivas divergentes e pela especificidade dos contextos (PINAR, 2010b). Não se trata, assim, de uma crise que lança a dúvida sobre o que é o currículo como campo de estudo, mas que resulta de uma identidade que é teoricamente "complexa e diversificada" (PINAR, 2007b, p. 25), isto é, uma complexidade teórica que torna o campo mais interessante na problematização da educação e formação. Deste modo, a diversidade teórica é uma das carateristicas dos estudos curriculares, não sendo interpretada como uma fraqueza ou limitação, mas como algo que faz parte da sua afirmação epistemológica. Na realidade, e observa William Pinar (2010a, p. 528), esta diversidade é colocada em causa pelo facto de os discursos centrados nos "resultados académicos" e nos "testes estandardizados" estarem a obliterar a "realidade individual dos professores e dos alunos nas escolas do presente", onde o conhecimento é tratado como competência (PACHECO, 2011b), ou como se não tivesse conteúdos, crítica que também é partilhada por Michael Young (2010a). 
Aliás, a crise de identidade tem sido um aspeto amplamente reconhecido (PINAR, REYNOLDS, SLATTERY, TAUBMAN, 1995), sendo necessário estabelecer as continuidades e descontinuidades entre as diversas abordagens teóricas que representam o currículo como um dispositivo burocrático e técnico (KLIEBARD, 1970) e como um projeto de compreensão (Reconceptualização e Pós-reconceptualização) (PACHECO, 2009; SLATERY, 2006; MORRIS, 2005; PINAR, 1975, 1979, 2006; PINAR; GRUMET, 1981).

Enquadrado em abordagens amplamente ecléticas e teóricas - fenomenologia, autobiografia, existencialismo, pragmatismo, desconstrução, teoria queer, teoria crítica, pós-estruturalismo, estudos de género, hermenêutica, teoria da complexidade (SCHUBERT, 2008; MALEWSKI, 2010b) -, o campo dos estudos curriculares comporta movimentos que mantêm vigoroso o superdiscurso da tradição norte-americana (AUTIO, 2006), ainda que muitas das ideias sejam tributárias do pensamento de Michel Foucault, Gilles Deleuze e Jacques Derrida. Quer dizer: se a diversidade e a conflitualidade constituem marcas distintas da sua caraterização teórica, não há dúvida de que os estudos curriculares constituem, no presente, um campo "academicamente produtivo" (GAZTAMBID-FERNÁNDEZ, THIESSEN (2009, p. 14), embora com um "futuro incerto" (PINAR, 2007a, p. 18).

Para além do desafio da identidade, que sempre se manifestará, pois o currículo como projeto de formação, espacial e temporalmente definido em função de determinados contextos, é algo inacabado, os estudos curriculares são confrontados com as abordagens que se cruzam nas políticas que conduzem a processos e práticas de decisão em situações específicas. Um dos princípios teóricos da pós-modernidade diz respeito à refutação das metanarrativas como fator explicativo da realidade. Neste caso, cabe perguntar: o currículo é uma metanarrativa?

Para Leo Cherryholmes (1993) as verdades absolutas estão presentes no próprio edifício curricular, quando identifica como determinantes da sua construção técnica, 0 Rationale Tyler, a pedagogia por objetivos e a estrutura das disciplinas. Não é suposto que estas metanarrativas tenham perdido validade, nem tampouco que tenham sido secundarizadas, mesmo que, agora, os discursos valorizem a descentralização, a autonomia, o projeto e a profissionalidade, entre outras referências.

A diversidade do campo dos estudos curriculares é amplamente reconhecida, especialmente depois da incorporação de novas perspetivas conceptuais, por exemplo, das teorias politicas, multiculturais, fenomenológicas, pós-modernas, pós-estruturais, autobiográficas, estéticas, teológicas e internacionais (PINAR, 2008). E toda esta identidade complexa dos estudos curriculares, que resulta da confrontação entre diferentes perspetivas concetuais, é ampliada pela discussão em torno da globalização e da internacionalização, dois termos que não têm o mesmo significado, sendo dois processos bem diferentes, representado, aquele, uma prática 
efetiva de homogeneização e, este, uma prática de diálogo. Porém, e atendendo às condições de diálogo existentes, a internacionalização facilmente se torna num processo hegemónico, não deixando de existir, no caso dos estudos curriculares, 0 superdiscurso norte-americano, canadiano, britânico e australiano.

Se já foi considerada uma mudança paradigmática (PINAR, 2003), a internacionalização do campo dos estudos curriculares necessita de ser analisada pelos novos parâmetros de uma abordagem global do currículo, nos termos do que conta como conhecimento e no modo como a lógica de mercado estabelece princípios para a discussão do conhecimento baseado nos resultados. No entendimento de Noel Gough (2000, p. 329), "a internacionalização dos estudos curriculares pode ser compreendida como a criação de espaços transnacionais nos quais as tradições de conhecimento local na investigação curricular podem ser protagonizadas em conjunto e não como representações locais de uma transladação curricular dentro de um discurso universal".

Trata-se de contestar a existência de uma tendência homogénea, presente na proposta de uma teoria política, económica e culturalmente globalizada (RITZER, 2007; CLARENCE, 2011), e que constituiria o suporte de uma abordagem curricular global, politicamente ancorada no valor económico do conhecimento, na reafirmação do currículo nacional, cada vez mais interligado pelo sistema económico mundial, por uma agenda globalmente estruturada (TEODORO, 2010) e por uma cultura de avaliação orientada para a performatividade dos resultados comparativos e resultantes de avaliações externas estandardizadas.

Deste modo, e interrogando-se quanto à possibilidade de o currículo poder vir a tornar-se global, Kathryn Anderson-Levitt (2008, p. 364) analisa que, por um lado, existe uma "similaridade a nível mundial" e, por outro, o currículo "difere ao nível da sala de aula", fazendo com que predomine uma linguagem comum em termos de reformas curriculares, que são impostas pelas agendas dos organismos transnacionais e supranacionais direcionadas para o core curriculum. Esta tendência não é suficientemente impeditiva da diversidade que se observa a nivel local, pois "o que atualmente acontece nas salas de aula varia genericamente no mundo" (ibid., p. 363). Não é aceitável dizer, assim, que há uma única solução para a educação e que há um único dispositivo curricular, como se fossem o suporte de um professor global (MAGUIRE, 2010).

Operando a globalização no plano do currículo prescrito, é ao nível da sala de aula e das experiências locais e singulares, com a valorização da identidade/diferença e com a rejeição de uma linguagem universal (CONNELLY; XU, 2008) que ganha espaço a abordagem cosmopolita do currículo, no entendimento do que é a participação do sujeito no diálogo intergeracional (GRUMET, 1988). A mundialidade de um currículo cosmopolita, para William Pinar (2009, p. 8), implica reconhecer, em primeiro lugar, "a educação geral como algo mais do que a introdução às grandes obras e a memorização do conhecimento essencial e, em segundo, a personificação do individual". Significa, 
ainda, a valorização do "self" e do "sujeito" em diálogo com os "outros", bem como a sua criatividade, a rejeição de abordagens que universalizam a identidade, a diferença e a diversidade, (KENNEDY, 2011; GAZTAMBID-FERNANDEZ, THIESSEN, 2009; BAKER, 2010; CARLSON, 2009; TODD, 2009; HANSEN, BURDICK-SHEPHERD, CAMMARANO, OBELLEIRO, 2009, HANSEN, 2008), para além da exploração dos "receios, expetativas e esperanças" dos sujeitos intervenientes no currículo (GOUGH, 2010, p. 31).

Estas duas abordagens espelham a face dual do projeto curricular que opera pela globalização e pelo cosmopolitismo: a global como um processo político e económico (DILLON, 2009) e a cosmopolita como um processo hermenêutico e pedagógico.

\section{Tradições dos estudos curriculares em Portugal ${ }^{2}$}

A questão da identidade dos estudos curriculares está dependente de uma conflitualidade construtiva, como descrevi no ponto antecedente, ao nível interdisciplinar, com a demarcação de territórios conceptuais que têm sido aglutinados pela pretensa homogeneização das políticas curriculares. Neste sentido, torna-se necessário reconhecer que nos estudos curriculares há perspetivas diferentes, ligadas a contextos e a atores sociais diversos, que procuro sinalizar, de seguida, para a realidade portuguesa, ao nivel das tradições.

No texto Os Estudos Curriculares em Portugal: Génese, Consolidação e Europeização (PACHECO; SEABRA, 2013) identificam-se as tradições curriculares baseadas na escola e na academia, no seguimento da distinção realizada por William Pinar (2008), a que acrescento, neste texto, a tradição profissional.

Com efeito, é a tradição escolar que está na génese do currículo em Portugal, pois as questões curriculares começam por ser predominantemente da esfera da decisão governamental e da ação das escolas, sem que haja, primeiramente, um enquadramento teórico ao nivel de um campo estruturado de saberes. Nesse caso, o currículo corresponde a um plano nacional de disciplinas organizadoras do conhecimento escolar, politicamente implementado em escolas que são reguladas administrativamente na base de uma hierarquia decisional muito técnica.

Esta perspetiva stricto sensu de currículo caracteriza-se por um conhecimentofora-de contexto (APPLEBE, 1996, p. 30), que se torna no referencial do ensino e da aprendizagem igual para todos, na ressuscitação do ideal de Comenius, e por mudanças políticas na organização curricular marcadas pela compartamentalização (Westbury, 2008), isto é, alterações nas margens do sistema e não na sua estrutura básica, para que seja possível a estabilidade e a legitimação do currículo.

\footnotetext{
2 Apesar de serem citados, neste ponto, autores de outras nacionalidades, incluindo Brasil, as questões em debate têm um recorte analítico regional, com incidência na realidade portuguesa.
} 
Entendido desse modo, o currículo busca os seus argumentos explicativos no princípio taylorista da gestão eficiente, o que lhe garante uma sustentabilidade prática, já que na génese dos estudos curriculares está um interesse administrativo (PINAR, 2007a), e nos conceitos estruturantes da psicologia, sobretudo os que podem validar o currículo como uma teoria de instrução e, mais ainda, como uma prática sem teoria. No dizer de Maria Teresa Estrela (2011, p. 32), "a origem dos estudos curriculares em problemas da prática, desligado de uma matriz disciplinar da qual dependessem, é salientada por alguns autores do currículo". É pela tradição escolar que se estabelece uma relação conceptual forte entre psicologia e currículo, convertendo-se este numa ciência do ensino e da aprendizagem, dependente de processos, procedimentos, estratégias e métodos (MOREIRA, 2003b), bem como de uma racionalidade instrumental.

A colonização pela psicologia estreita-se a partir do momento em que o currículo é entendido como "uma série estruturada de resultados pretendidos de aprendizagem" (Johnson, 1980, p. 18), aliás presente quer nos trabalhos de Bobbitt (1918), Chartres (1923) e Tyler (1949), quer nas propostas de Bruner (1960), quer ainda nas políticas de accountability, mormente na valorização da funcionalidade avaliativa das metas de aprendizagem (PACHECO, 2011c).

Tal domínio é responsável pela produção, nos estudos curriculares, do superdiscurso fundacional da racionalidade tyleriana (AUTIO, 2006), com contributos marcantes no modo de entender o processo de desenvolvimento do currículo e na introdução de perspetivas normativas e prescritivas. Um outro contributo é identificado pela valorização do ensino e da aprendizagem quando comparados com o conhecimento, pelo que a dimensão psicológica do currículo comporta, essencialmente, abordagens relativas ao seu processo de desenvolvimento ou ao seu espaço didático. É, assim, que José Gil (2000a, p. 336-337) entende que "o programa cognitivo da escola pouco deve à teoria (e menos ainda à "realidade") psicológica; elaborou-se em função do desenvolvimento das ciências, da classificação das disciplinas e dos condicionalismos sociais. Mas tentou sempre justificar-se pela psicologia".

A tradição académica reconhece-se pela identidade institucional dos estudos curriculares como campo de estudo nas instituições de ensino superior, se bem que, na realidade portuguesa, seja amplamente dominante a perspetiva do currículo como decisão governamental. Porém, esta tradição emerge em Portugal, e mantém-se, há que dizê-lo com frontalidade, de um modo disperso, fragmentado e difuso em termos de uma abordagem teórica, o que explica a sua grande diversidade e incoerência epistemológica, necessitando de uma perspetiva minimamente coerente, sobretudo quando são confrontados os conceitos de currículo, didática, pedagogia, conhecimento, ensino e aprendizagem. Não há, e uma vez analisados os estudos curriculares nas instituições de ensino superior, em Portugal, um denominador comum para a sua afirmação epistemológica, principalmente quando esta se deve a fatores exógenos à conceptualização do campo. 
Todavia, é da tradição académica que resulta a valorização do currículo como conhecimento, principalmente a partir dos estudos sociológicos. Embora a sua base seja essencialmente filosófica, com a afirmação do racionalismo académico, presente na génese da educação e reafirmado com a institucionalização da educação em projetos formais de escolarização, é pelo contributo da sociologia que o conhecimento se institui num conceito-chave do currículo (MOREIRA, 2011), sendo considerado o conhecimento escolar num "objeto de ensino e de investigação incontornável no debate político contemporâneo do campo do currículo" (GABRIEL, 2011, p. 37).

Dentre os vários desafios, ou tarefas epistemológicas para Ana Mouraz (2011), colocados na clarificação do objeto de estudo consta esta interrogação, formulada por Herbert Spencer, em 1860: Que conhecimento é mais valioso?

Trata-se de uma interrogação complexa, frequentemente revisitada pela sociologia em função de dinâmicas de género, classe e raça (APPLE, 1999, 2010), pelos estudos culturais através dos conceitos de identidade e diferença (VEIGA-NETO, 2011, ROLDÃO, 2003; SOUSA, 2010), pelos estudos de globalização (LIPOVETSKY, SERROY, 2010; RITZER, 2007; GOUGH, 2004; PINAR, 2003) e pela psicanálise com base na noção de sujeito ${ }^{3}$ (PINAR, 2010a, 2010b, PINAR 2010c).

Michael Young (1971, 2010a) tem sido um autor marcante na proposta de uma teorização que tem por base de argumentação a centralidade do conhecimento, primeiro, na década de 1970, pela análise crítica da doutrina do controlo, no âmbito dos princípios da nova sociologia do conhecimento, depois, na década de 2000, pela teoria sociorealista do conhecimento. Tendo a sua origem num processo de seleção, fortemente controlado, o conhecimento escolar faz parte da cultura social ampla, sendo o resultado de diversas escolhas. A esse respeito, adverte Michael Young (1971, p. 24): os sociólogos "esqueceram-se de que a educação não é um produto tal como carros e pão, mas uma seleção e organização de um conhecimento válido num tempo particular que envolve escolhas conscientes ou inconscientes". Por isso, o que conta como conhecimento escolar é problemático, pois, no âmbito da estrutura chamada escola, todo o processo de transformação curricular é socialmente construído, inerente a questões de poder e formas de discutir os critérios de verdade em termos epistemológicos.

Uma outra análise fundamental tem que ver com a diferenciação do conhecimento e com os princípios da sua organização escolar. Baseando-se em Durkheim, Vygotsky e Bernstein, Michael Young $(2010 a, 2010 b)$ discute esta questão, salientando a urgência de o conhecimento voltar a ser colocado como tema central dos estudos curriculares.

3 Para Marcel Postic (20007, p. 115), “os investigadores do campo psicanalítico insistem na noção de autonomia do sujeito e a relação pedagógica permite que o aluno aceda à interiorização das regras e adquira um estatuto de sujeito como desejo, capaz de romper com os seus laços de dependência e de construir a sua identidade". 
Esta centralidade prende-se aos tipos de conhecimento valorizados pela educação e pela escola. A diferenciação coloca, de um lado, o conhecimento codificado e teórico, do outro, o conhecimento tácito, prático e do dia a dia, criando-se uma dicotomia entre o que é formal e cognitivamente superior, e o que é informal e experiencialmente secundário. Tal dicotomia pressupõe dizer que há um conhecimento poderoso, o de indole disciplinar, e um conhecimento da vida quotidiana, transitório e local, de natureza experiencial, aquele mais ligado à organização tradicional da escola e este mais próximo de uma escola marcada por imperativos económicos.

Assim, Michael Young (2010a, p.138) defende uma teoria sociorrelaista do conhecimento aplicada ao currículo, pois um currículo do futuro "necessita de tratar o conhecimento como elemento distinto e irredutivel, no processo histórico ao longo do qual as pessoas continuam a procurar superar as circunstâncias em que se encontram", ao mesmo tempo que lutam contra a marginalização do conhecimento nos estudos curriculares, na medida em que "a aquisição do conhecimento é o propósito-chave que distingue a educação (...) de todas as outras atividades" (ibid., p. 178).

Não é sem razão, por isso, que Michael Young afirma que a crise da teoria curricular advém das políticas neoliberais e que, presentemente, "temos uma teoria curricular marginalizada que oferece críticas dos interesses envolvidos nos curricula existentes, mas não avança com quaisquer alternativas" (ibid., p. 175). Todas essas suas ideias baseiam-se na crítica que faz à pós-modernidade, à expressão do conhecimento do quotidiano como fonte da aprendizagem, à noção de competências genéricas sem conteúdos, à abordagem baseada nos resultados, os quais devem obedecer a padrões ou standards, ao conceito de aprendizagem ao longo da vida de cariz qualificante e à noção de ensino como conversação. Tais críticas encontram eco nas ideias de Maria Teresa Estrela $(2011$, p. 31) quando sublinha a existência, na concepção aberta de currículo, de ideias "subjetivistas e criativas de um pensamento influenciado pela fenomenologia e pelo pós-modernismo". Porém, é uma discussão que necessita de ser aprofundada, com a recolocação do sujeito na construção privada e pública do currículo.

A tradição profissional deriva da tradição académica e está legitimada pela universitarização da formação profissional, como reconhece Manuela Esteves (2002, p. 40), quando fala de "um corpo de conhecimentos científicos acumulados e disponiveis de que a universidade deteria o património e que poderiam ser investidos na preparação para a profissão em referência", e pela emergência de posicionamentos sociológicos e psicanalíticos ligados, por exemplo, às identidades profissionais.

Ao tornar-se num eixo fundamental das ciências da educação, a formação de educadores, professores e de outros profissionais adquire uma justificação teórico-prática que não pode ser dissociada da dimensão curricular, tanto pela sua natureza dos modelos e teorias de formação, quanto pelos processos e práticas de desenvolvimento profissional (FLORES, 2011; MORGADO, 2005; DAY, 2001). 
Dada a sua natureza formal ligada à organização escolar e a sua dimensão académica, com a discussão em torno do conhecimento e da formação profissional, os estudos curriculares têm na sua génese e consolidação, em Portugal, tradições diferentes, mas complementares, que tornam mais inteligivel o modo como se têm estruturado num campo teórico-prático, muito marcado, por um lado, pela indefinição académica e, por outro, pelo consenso escolar.

\section{Desafios metodológicos dos estudos curriculares}

Para além dos desafios teóricos, que podem ser analisados em função das tradições que são construídas em cada contexto nacional, ainda que as similaridades possam ser um denominador comum a muitos paises, principalmente quando está em curso a construção de agendas políticas regionais, de natureza transnacional, a pesquisa curricular constitui-se num desafio a ser abordado, embora o faça de modo particular, neste ponto, porque considero somente a realidade portuguesa.

Como em qualquer campo de conhecimento, a pesquisa em currículo depende de objeto de uma metodologia. Porém, e dada a sua tendência para o controlo administrativo e para a burocratização das suas práticas, o objeto de pesquisa tem ficado prisioneiro de uma agenda política, apesar da complexidade e da pujança das temáticas investigadas (ROLDÃO, 2003, 2005a).

Pujança na proliferação de trabalhos académicos e na realização de estudos no âmbito dos grupos de pesquisa; complexidade, decerto, nos seus conteúdos. Tal como acontece em educação (CANÁRIO, 2005; ROLDÃO, 2005b; LIMA, 2003; ESTRELA, 1992), a pesquisa curricular, e refiro-me basicamente à que tem sido realizada em Portugal (PACHECO, 2002, 2007), está aprisionada pela agenda política, que tem estabelecido o objeto de estudo pelas mudanças operadas na organização curricular do sistema educativo, como também é determinada pelos critérios economicistas das agências de financiamento (PACHECO, 2010). Além disso, o que traz responsabilidades acrescidas aos que pertencem ao campo, muita da pesquisa curricular realizada, nas últimas décadas em Portugal, tem originado um conhecimento próximo da opinião, com referências omissas a autores principais dos estudos curriculares, ao mesmo tempo que tem sido utilizada uma metodologia qualitativa pobre, sobretudo no modo artesanal e intuitivo como é feita a análise de conteúdo e são procurados os critérios de validade científica. Em parte, esta situação resulta do que Maria Teresa Estrela (2007, p. 36) chama "deriva ideológica" e "deriva generalizadora", podendo-se acrescentar, de igual modo, e utilizando-se ideias de Maria do Céu Roldão (2003), a deriva normativista.

Também devido ao peso da tradição escolar e do ciclo político, que define a agenda, a pesquisa curricular portuguesa centra-se mais nas fases do currículo prescrito, apresentado, moldado/planificado e avaliado que propriamente na fase do currículo-em- 
ação, deixando-se de lado as estratégias de observação letiva (ESTRELA, 2004). A expulsão do currículo da sala de aula, e mesmo dos espaços pedagógicos de formação, em termos de investigação é algo que tem contribuído para a didatização do currículo, deixando-se essa tarefa para as didáticas específicas. Desse modo, e recorrendo também à realidade brasileira, "as teorizações que temos produzido por meio de nossas pesquisas não têm contribuído, como gostaríamos, para enriquecer a prática curricular em nossas salas de aula e promover mais aprendizagem. Ou seja, a teoria e a prática não se encontram tanto como seria de desejar" (GARCIA; MOREIRA, 2003, p. 7).

Uma outra questão, que se referencia na análise da pesquisa curricular realizada em Portugal, consiste na tendência para a sobrevalorização dos discursos dos professores ${ }^{4}$ e formadores, com focalização excessiva no seu agir reflexivo, conquanto fosse possivel ignorar os outros lugares-chave (contexto, aluno e conteúdos) propostos por Joseph Schwab (1970).

Com efeito, a pesquisa curricular, que se faz em Portugal, não é congruente com a complexidade teórica do campo, mais ainda quando às problemáticas emergentes são associadas os discursos de base opinativa, surgindo como texto científico o que, na realidade, tem originado a doxa curricular, ou seja, a existência de textos discursivos desligados da realidade educacional e dos contextos em que as questões curriculares são decididas, nos diversos contextos e níveis, pelos atores sociais.

\section{Conclusão}

Sendo um campo de elevada permeabilidade teórica, com práticas que são quase comuns ao nível da educação e formação, com uma investigação relevante, mas ainda com certas fragilidades, os estudos curriculares enfrentam desafios que necessitam de ser discutidos e ponderados no interior das ciências da educação e das ciências sociais. Porque a sua identidade complexa não constitui per se um problema a ser solucionado, mas uma perspetiva a ser debatida ao nivel da sua comunidade científica, os estudos curriculares são um campo de conhecimento que apresenta discussões e análises críticas da realidade educacional, configurada como um real inter-relacionado, complexo e multirreferencial. Pelos desafios teóricos, que são enunciados ao longo do texto, pode ser construída a ideia de que o campo dos estudos curriculares é marcado, de forma definitiva, por uma crise epistemológica, não só porque alberga perspetivas muito diferentes, bem como porque pode ser analisado pelo prisma da falta de uma identidade universalmente reconhecida. Porém, e como deixei claro nas ideias perfilhadas e desenvolvidas, a identidade do campo é uma questão em permanente discussão e este reconhecimento constitui em si um aspeto que o coloca numa discussão teórica aberta a outros campos e a outras análises.

4 No levantamento e caraterização da investigação curricular em Portugal, conclui-se que cerca de $2 / 3$ dos estudos das dissertações e teses têm como amostra/respondentes professores. cf. José Augusto Pacheco, 2002. 
Compreender-se-á melhor a diversidade da identidade dos estudos curriculares se forem analisadas o que se consideram ser as tradições curriculares, isto é, os espaços em que se opera a génese e se consolida uma determinada componente identitária, seja a que está ligada aos espaços escolares ou não escolares, seja a que diz respeito às instituições de ensino superior, seja, ainda, a que está focada na formação profissional.

Contudo, e porque as tradições constituem-se em lógicas que sedimentam políticas e práticas, é necessário discutir de que modo a globalização se torna num discurso que legitima agendas políticas que, por sua vez, contribui para a criação de uma legitimidade discursiva e consequente apropriação, pelos atores sociais, de modelos e práticas pretensamente neutrais. Para isso, é crucial que os estudos curriculares sejam entendidos na sua complexidade identitária, com a existência de diferentes perspetivas teóricas e tradições, não sendo possível aceitar a redução do conhecimento curricular um simplismo técnico ou mesmo a uma pesquisa meramente opinativa.

Quanto aos desafios metodológicos, é fundamental reconhecer que a pesquisa curricular tem sido redefinida pela agenda política e pelas agências de financiamento, sobretudo a partir do estudo da realidade portuguesa, nas últimas décadas. Esta redefinição consiste na regulação do objeto de pesquisa, geralmente associadas a temáticas politicamente produtivas, por exemplo, no âmbito de reformas e normativos, e na orientação para a busca de determinados resultados. Trata-se, com efeito, de uma pesquisa que segue agendas políticas cada vez mais interligadas a agendas transnacionais, incluindo perspetivas metodológicas precisas, com ênfase para o estudo quantitativo da realidade educacional. 0 mesmo resultado se observa com as agências de financiamento, cujo modelo de pesquisa segue agendas internacionalmente organizadas, com vista à uniformização de práticas curriculares.

Por isso, o futuro, sempre incerto, dos estudos curriculares encontra-se no reconhecimento de uma diversidade teórica, que contribui amplamente para a discussão crítica do que se entende por currículo como projeto de formação, e de uma investigação centrada no questionamento regulado por critérios de validação científica.

\section{Referências}

ALONSO, M. L. Inovação Curricular, Formação de Professores e Melhoria da Escola. Braga: Universidade do Minho, 1999.

ALVES, M. P. Currículo e Avaliação. Porto: Porto Editora, 2004.

ANDERSON-LEVITT, K. M. Globalization and Curriculum. In: CONNELLY, F. M. (Ed.). The Sage Handbook of Curriculum and Instruction. Los Angeles: Sage, 2008, p. 349-368. 
APPLE, M. W. On Being a Scholar/Activist in Education. In: SHORT, E. C.; L. J. WAKS (Ed.). Leaders in Curriculum Studies. Rotterdam: Sense Publishers, 2010, p. 1-17.

APPLE, M. W. Políticas Culturais e Educação. Porto: Porto Editora, 1999.

APPLEBEE, A. N. Curriculum as Conversation. Chicago: The University of Chicago Press, 1996.

AUTIO, T. Subjectivity, Curriculum, and Society: between and beyond German Didaktik and Anglo-American Curriculum Studies. Mahwah, NJ: Lawrence Erlbaum, 2006.

BAKER, B. Provincializing Curriculum?: on the preparation of subjectivity for globality. Curriculum Inquiry, v. 40, n. 2, p. 221-240, 2010.

BEYER, L.; LISTON, D. Curriculum in Conflict: social visions, educational agendas and progressive school reform. New York: Teachers College Press, 1996.

BOAVIDA, J.; AMADO, J. Ciências da Educação: epistemologia, identidade e perspectivas. Coimbra: Imprensa da Universidade de Coimbra, 2008.

BOBBITT, F. The Curriculum. New York: Hougthon Mifflin, 1918.

BOURDIEU, P. Para uma Sociologia da Ciência. Lisboa: Edições 70, 2004.

BRUNER, J. The process of Education. Cambridge: Harvard University Press, 1960.

CANÁRIO, C. 0 Impacte Social das Ciências da Educação. In: ESTRELA, A., MENDES, P.; CHOURIÇO, J. (Org.). O Estado da Arte em Educação. Porto: SPCE, 2005, p. 13-28.

CARSON, T. R. Internationalizing Curriculum: globalization and the worldliness of Curriculum Studies. Curriculum Inquiry, [S.I.], v. 39, n. 1, p. 145-158, 2009.

CARVALHO, A. D. Epistemologia das Ciências da Educação. Porto: Edições Afrontamento, 1986.

CHARLOT, B. Educação e Globalização: uma tentativa de colocar ordem no debate. Sísifo: Revista de Ciências da Educação, v. 4, p. 129-136, 2007.

CHARTERS, W. Curriculum Construction. New York: The Macmillan Company, 1923.

CHERRYHOLMES, C. Um Projeto Social para o Currículo: Perspetivas Pósestruturais. In: SILVA, T. T. (Org.). Teoria Educacional Crítica e Tempos Pósmodernos. Porto Alegre: Artes Médicas, 1993, p. 143-172. 
CLARENCE, K. Curriculum, Policy \& Globalization. Curriculum Inquiry, [S.I.], v. 41, n. 1, p. 57-61, 2011.

CONNELLY, F. M.; XU, S. The Landscape of Curriculum and Instruction: diversity and Continuity. In: CONNELLY, F. M. (Ed.). The Sage Handbook of Curriculum and Instruction. Los Angeles: Sage, 2008, p. 514-533.

DAY, C. Desenvolvimento Profissional de Professores. Porto: Porto Editora, 2001.

DILLON, J. T. The questions of curriculum. Journal of Curriculum Studies, [S.I.], v. 41, n. 3, p. 343-359, 2009.

DOYLE, W. Curriculum and Pedagogy. In: JACKSON, P. (Ed). Handbook of Research on Curriculum. New York: Macmillan Publishing Company, 1992, p. 486-516.

ESTEVES, M. M. A Investigação enquanto estratégia de formação de professores. Lisboa: Instituto de Inovação Educacional, 2002.

ESTRELA, A. O Tempo e o Lugar das Ciências da Educação. Porto: S.P.C.E.; Porto Editora, 1999.

.Pedagogia, Ciência da Educação?. Porto: Porto Editora, 1992.

Teoria e Observação de classes. Porto: Porto Editora, 2004.

ESTRELA, M. T. As Ciências da Educação hoje. In: SOUSA, J. M. (Org.). Educação para o sucesso: políticas e atores. CONGRESSO DA SOCIEDADE PORTUGUESA DE CIÊNCIAS DA EDUCAÇÃO, 9., 2007. Trabalhos apresentados... Madeira: Universidade da Madeira/ SPCE, 2007.

. Complexidade da Epistemologia do Currículo. In: LEITE, C., PACHECO, J. A., MOREIRA, A. F.; MOURAZ, A. (Org.). Políticas, fundamentos e práticas do currículo. Porto: Porto Editora, 2011, p. 29-36.

FERNANDES, P. O Currículo do Ensino Básico em Portugal: Políticas, Perspetivas e Desafios. Porto: Porto Editora, 2011.

FLORES, M. A. Curriculum of Initial Teacher Education in Portugal: new contexts, old problems. Journal of Education for Teaching, [S.I.], v. 37, n. 4, p. 461- 470, 2011.

GABRIEL, C. T. Currículo e Epistemologia: sobre fronteiras do conhecimento escolar. In: LEITE, C., PACHECO, J. A, MOREIRA, A. F.; MOURAZ, A. (Org.). Políticas, fundamentos e práticas do Currículo. Porto: Porto Editora, 2011, p. 37-43. 
GARCIA, R. L.; MOREIRA, A. F. Currículo na contemporaneidade: incertezas e desafios. São Paulo: Cortez Editora, 2003.

GASPAR, I.; ROLDÃO, M. C. Elementos do desenvolvimento curricular. Lisboa: Universidade Aberta, 2007.

GAZTAMBID-FERNÁNDEZ, R.; THIESSEN, D. There's nothing as theoretical as good practice. Curriculum Inquiry, [S.I.], v. 39, n. 1, p. 1-14, 2009.

GIL, J. Disciplinas. In: ROMANO, R. (Dir.). Conhecimento. Lisboa: Imprensa Nacional-Casa da Moeda, Enciclopédia Einaudi, 2000, p. 329-348.

GOODLAD, J. I.; SU, Z. Organization of the Curriculum. In: JACKSON, P. (Ed.). Handbook of Research on Curriculum. New York: MacMillan Publishing Company, 1992, p. 327-344.

GOODSON, I. Currículo em mudança. Porto: Porto Editora, 2001.

GOUGH, N. Futures in Curriculum: the anticipatory generation of alternatives. Critical Studies in Education, [S.I.], v. 39, n. 1, p. 1-14, 2009. DOI: 10.1080/17508488709556219. Acesso em: 26 jun. 2010.

GOUGH, N. Locating Curriculum Studies in the Global Village. Journal of Curriculum Studies, [S.I.], v. 32, n. 2, p. 329-342, 2000.

GOUGH, Noel. A vision for Transnational Curriculum Inquiry. Transnational Curriculum Inquiry, [S.I.], v. 1, n. 1, 2004. Disponivel em: < http://nitinat.library. ubc.ca/ojs/index.php/tci. . . Acesso em: 13 jan. 2012.

GRUMET, M. R. Bitter milk: women and teaching. Amherst: The University of Massachusetts Press, 1988.

HANSEN, D. T. Curriculum and the Idea of Cosmopolitan Inheritance. Journal of Curriculum Studies, [S.I.], v. 40, n. 3, p. 289-312, 2008. Disponivel em:< http:// www2.uwstout.edu/content/jaaacs/vol2/pinar_exile.htm>. Acesso em: jan. 2012.

HANSEN, D. T., BURDICK-SHEPHERD, S., CAMMARANO, C.,; OBELLEIRO, G. Education, values, and valuing in cosmopolitan perspective. Curriculum Inquiry, [S.I.], v. 39, n. 5, p. 587-612, 2009.

JOHNSON, M. Definições e modelos na teoria do currículo. In: MESSICK, R., PAIXÃO, L.; BASTOS, L. R. (Org.). Currículo: análise e debate. Rio de Janeiro: Zahar Editores, 1980, p. 13-32. 
KENNEDY, R. Toward a cosmopolitan curriculum of forgiveness. Curriculum Inquiry, [S.I.], v. 41, n. 3, p. 373-393, 2011.

KLIEBARD, H. K. The tyler rationale. The School Review, [S.I.], v. 78, n. 2, p. 259-272, 1970.

LEITE, C. O Currículo e o Multiculturalismo no Sistema Educativo Português. Lisboa: Fundação Calouste Gulbenkian, 2002.

LIBÂNEO, J. C. (Org.). Temas de Pedagogia: diálogos entre currículo e didática. São Paulo, Cortez Editora, 2011.

LIMA, L. Editorial. Investigar em Educação, São Paulo, v. 2, n.1, p. 7-11, 2003.

LIPOVETSKY, G.; SERROY, J. A. Cultura-mundo: resposta a uma sociedade desorientada. Lisboa: Edições 70, 2010.

MACEDO, E.; LOPES, A. C. Teorias de Currículo. São Paulo: Editora Cortez, 2011.

MAGUIRE, M. (2010). Towards a sociology of the global teacher. In: APPLE, M.; BALL, S.; GANDIN, L. (Ed.). The Routledge international handbook of the Sociology of Education. New York: Routledge, 2010, p. 58-68.

MALEWSKI, E. (Ed.). Curriculum studies handbook: the next moment. New York: Routledge, 2010a.

MALEWSKI, E. A way of knowing in the future of curriculum studies. In:

MALEWSKI, E. (Ed.). Curriculum studies handbook: the next moment. New York: Routledge, 2010b, p. 534-539.

MARTINAND, L. Didática e didáticas: esboço problemático. In: ESTRELA, A. (Org.). Investigação em educação, teorias e práticas (1960-2005). Lisboa: Educa, 2007, p. 147-168.

MOREIRA, A. F. A Qualidade e o Currículo na Escola Básica Brasileira. In: LEITE, C., PACHECO, J. A, MOREIRA, A. F.; MOURAZ, A. (Org.). Políticas, Fundamentos e Práticas do Currículo. Porto: Porto Editora, 2011, p.319-334.

MOREIRA, A. F. The curriculum field in Brazil: emergence and consolidation. In: PINAR, W. F. (Ed.). International Handbook of Curriculum Research. London: Lawrence Erlbaum Associates Publishers, 2003a. p. 171-184.

MOREIRA, A. F. Por entre ficções e descentramentos: discussões atuais de Currículo e a Psicologia da Educação. In: REUNIÃO ANUAL DA ANPED, 26., 2003. Anais... Poço de Caldas: ANPED, $2003 \mathrm{~b}$. 
MORGADO, J. C. Currículo e Profissionalidade Docente. Porto: Porto Editora, 2005.

MORRIS, M. Back up group: here comes the (post) reconceptualization. Journal of Curriculum Theorizing, [S.I.], v. 21, n. 4, p. 3-12, 2005.

MOURAZ, A. As Tarefas Epistemológicas dos Estudos Curriculares. In: LEITE, C., PACHECO, J.A, MOREIRA, A. F.; MOURAZ, A. (Org.). Políticas, Fundamentos e Práticas do Currículo. Porto: Porto Editora, 2011, p. 44-52.

NÓVOA, A. Eu pedagogo me confesso: diálogos com Rui Grácio. Inovação, São Paulo, v. 14, n. 1-2, p. 9-33, 2001.

OLIVEIRA, M. R. Didática: ruptura, compromisso e pesquisa. 3. ed. Campinas: Papirus Editora, 2001.

OLIVEIRA, M. R. A Reconstrução da didática: elementos teórico-metodológicos. 4. ed. Campinas: Papirus Editora, 2002.

OLIVEIRA, M. R. A Prática de Ensino da Didática no Brasil: introduzindo a temática. 12 ed. In: ANDRÉ, M. E.; OLIVEIRA, M. R. (Org.). Alternativas no Ensino da Didática. Campinas: Papirus Editora, 2011, p. 7-18.

PACHECO, J. A. Notas para uma síntese de uma década de consolidação dos estudos curriculares. Investigar em Educação, São Paulo, v. 1, n. 1, p. 227-273, 2002.

PACHECO, J. A. Estudos Curriculares: para a compreensão crítica da educação. Porto: Porto Editora, 2005.

PACHECO, J. A. Currículo: teoria e práxis. 3. ed. Porto: Porto Editora, 2006.

PACHECO, J. A. Currículo, investigação e mudança. In: CNE (Org.). A educação em Portugal (1986-2006): alguns contributos de investigação. Lisboa: CNE, 2007, p. 79-148.

PACHECO, J. A. Whole, bright, deep with understanding: life story and Politics of Curriculum Studies: In-between William Pinar and Ivor Goodson. Rotterdam/ Taipei: Sense Publishers, 2009.

PACHECO, J. A. Ciências da Educação e Investigação: o pesadelo que é o presente. Sísifo, Revista de Ciências da Educação, [S.I.], v. 12, p. 15-18, 2010. Disponível em: < http://sisifo.fpce.ul.pt.>. Acesso em: 26 abr. 2010. 
PACHECO, J. A. Curriculum studies: the State of the Field. In: LEITE, C., PACHECO, J. A, MOREIRA, A. F.; MOURAZ, A. (Org.). Políticas, Fundamentos e Práticas do Currículo. Porto: Porto Editora, 2011a, p. 44-52.

PACHECO, J. A. Discursos e lugares das Competências em Contextos de Educação e Formação. Porto: Porto Editora, 2011b.

PACHECO, J. A. Currículo e Gestão Escolar no Contexto das Políticas Educacionais. Revista Brasileira de Administração Educacional, São Paulo, v. 20, n. 36, p. 115-138, 2011 c.

PACHECO, J. A. Curriculum Studies: what is the Field today?. Journal of The American Association for the Advancement of Curriculum Studies, [S.I], v. 8, n. 1. p. 1-25, 2012.

PACHECO, J. A.; SEABRA, F. S. Curriculum Field in Portugal: emergence, research, and europeanization. In: PINAR, W.; AUTIO, T. (Org.). International Handbook of Curriculum Research. London: Lawrence Erlbaum Associates, Publishers, 2013.

PAGE, R. N. Foreword. In: SHORT, E. C.; WAKS, L. J. (Ed.). Leaders in Curriculum Studies: Intellectual Self-Portraits. Rotterdam: Sense Publishers, 2009.

PINAR, W. F. (Ed.). Curriculum Theorizing: the reconceptualists. Berkeley, CA: McCutchan, 1975.

PINAR, W. F. What is the reconceptualization?. Journal of Curriculum Theorizing, [S.I.], v. 1, n. 1, p. 93-104, 1979.

PINAR, W. F. (Ed.). International Handbook of Curriculum Research. London: Lawrence Erlbaum Associates Publishers, 2003.

PINAR, W. F. The Synoptic text today and other essays: curriculum development after reconceptualization. New York: Peter Lang, 2006.

PINAR, W. O Que é a teoria do Currículo? Porto: Porto Editora, 2007a.

PINAR, W. F. Intellectual advancement through disciplinarily: verticality and horizontality in curriculum studies. Rotterdam: Sense Publishers, 2007b.

PINAR, W. F. Curriculum Theory since 1950, crisis, reconceptualization, internationalization. In: CONNELLY, M.; FANG, H.; PHILLION, J. (Ed.). The Sage Handbook of Curriculum and Instruction. Los Angeles: Sage, 2008, p. 491-513. 
PINAR, W. F. The Worldliness of a Cosmopolitan Education: passionate lives in public service. New York: Routledge, 2009.

PINAR, W. F. The next moment. In: MALEWSKI, E. (Ed.). Curriculum Studies Handbook: the next moment. New York: Routledge, 2010a, p. 528-533.

PINAR, W. F. The Primacy of the Particular. In: MALEWSKI, E. (Ed.). Curriculum Studies Handbook: the next moment. New York: Routledge, 2010b, p. 143-152.

PINAR, W. F. Introduction. In: PINAR, W. F. (Ed.). Curriculum Studies in South Africa: intellectual Histories \& Present Circumstances. New York: Palgrave Macmillan, 2010c, p. 1-18.

PINAR, W. F. The character of curriculum studies: bildung, currere, and the recurring of the subject. New York: Palgrave Macmillan, 2011.

PINAR, W. F.; GRUMET, M. R. Theory and Practice and the Reconceptualization of Curriculum Studies. In: LAWN, M.; BARTON, L. (Ed.). Rethinking Curriculum Studies: a radical approach. New York: Croom Helm London, 1981, p. 20-42.

PINAR, W. F., REYNOLDS, W. M, SLATTERY, P.; TAUBMAN, P. M. (Ed.). Understanding curriculum: an introduction to the Study of Historical and Contemporary Curriculum Discourses. New York: Peter Lang, 1995.

POPPER, K. O Mito do contexto: em defesa da Ciência e da Racionalidade. Lisboa: Edições 70, 2009.

RITZER, G. The Globalization of nothing. 2. ed. London: Pine Forge Press, 2007.

ROLDÃO, M. C. O Currículo como projeto: o papel das Escolas e dos Professores. In: MARQUES, R.; ROLDÃO, M. C. (Org.). Reorganização e Gestão Curricular no Ensino Básico. Lisboa: Texto Editora, 1998, p. 11-21.

ROLDÃO, M. C. Os Professores e a Gestão do Currículo: perspectivas e práticas de análise. Porto: Porto Editora, 1999.

ROLDÃO, M. C. Diferenciação Curricular Revisitada. Porto: Porto Editora, 2003.

ROLDÃO, M. C. Formação e Práticas de Gestão Curricular: crenças e equívocos. Porto: Edições Asa, 2005a.

ROLDÃO, M. C. Saber Educativo e Culturas Profissionais: contributos para uma Construção/Desconstrução Epistemológica. In: CONGRESSO DA SOCIEDADE PORTUGUESA DE CIÊNCIAS DA EDUCAÇÃO, 7., 2005. Castelo Branco: SPCE, $2005 \mathrm{~b}$. 
ROLDÃO, M. C. Um currículo de currículos. Lisboa: Edições Cosmos, 2011.

SCHUBERT, W. H. Curriculum in theory. In: CONNELLY, F. M. (Ed.). The Sage Handbook of Curriculum and Instruction. Los Angeles: Sage, 2008, p. 391-395.

SCHWAB, J. J. The practical: a language for curriculum. The School Review, [S.I.], v. 78, n. 1, p. 1-23, 1970.

SLATTERY, P. Curriculum development in the Postmodern Era. 2. nd ed. New York: Routledge, 2006.

SNAZA, N. Thirteen theses in the question of state in Curriculum Studies. In: MALEWSKI, E. (Ed.). Curriculum Studies Handbook: the next moment. New York: Routledge, 2010, p. 43-56.

SILVA, T. T. Teorias do currículo: uma introdução crítica. Porto: Porto Editora, 2000.

SOUSA, F. Diferenciação Curricular e Deliberação Docente. Porto: Porto Editora, 2010.

TEODORO, A. Educação, Globalização e Neoliberalismo: os novos modos de Regulação Transnacional das Políticas de Educação. Lisboa: Edições Universitárias Lusófonas. 2010.

TODD, S. Toward an Imperfect Education: facing humanity, rethinking cosmopolitanism. Boulder \& London: Paradigm, 2009.

TYLER, R. Basic principles of Curriculum and Instruction. Chicago: The University of Chicago Press, 1949.

VEIGA-NETO, A. Equidade, igualdade e diferença: implicações para o Currículo. In: LEITE, C., PACHECO, J. A, MOREIRA, A. F.; MOURAZ, A. (Org.). Políticas, Fundamentos e Práticas do Currículo. Porto: Porto Editora, 2011, p. 54-61.

WEBER, M. Sobre a teoria das Ciências Sociais. Lisboa: Editora Presença, 1977.

WESTBURY, I. Making curricula: why do states make curricula, and how? In: CONNELLY, F. M. (Ed.). The Sage handbook of curriculum and instruction. Los Angeles: Sage Publications, 2008, p. 45-65.

YOUNG, M. An approach to the study of curricula as Socially Organized Knowledge. In: YOUNG, M. (Ed.). Knowledge and control: new directions for the Sociology of Education. London: Collier Macmillan Publishers, 1971, p. 19-46. 
YOUNG, M. Currículo e Conhecimento. Porto: Porto Editora, 2010a.

YOUNG, M. Curriculum theory and the problem of knowledge: a personal journey and an unfinished project. In: MALEWSKI, E. (Ed.), Curriculum Studies Handbook: the next moment. New York: Routledge, 2010b, p. 219-230.

Recebido em: 30/07/2012

Aceito para publicação em 13/02/2013

\section{Curriculum studies: theoretical and methodological challenges}

\section{Abstract}

With strong permeable disciplinary boundaries, the curriculum studies have addressed some theoretical and methodological challenges. In this article, I argument that the complex construction of curriculum studies' identity and the analysis of different approaches, occasionally contradictory, are challenges that need to be critically analyzed. The article also includes a brief review of the curriculum studies' traditions in Portugal and a particular approach about methodological challenges. Therefore, reading this article is crucial for undergraduate and postgraduate students as well as teachers and educators related either to the issues of education and training in general, and to the issues of curriculum, which includes also a reference to teaching and pedagogy.

Keywords: Curriculum Studies. Theory. Identity. Research. Traditions.

\section{Estudios Curriculares: desafíos teóricos y metodológicos Resumen}

Con las fronteras disciplinares muy permeables, los estudios curriculares han enfrentado algunos desafíos teóricos y metodológicos. En este artículo se argumenta que la construcción de la identidad y el análisis de diversos abordajes, a veces contradictorios, sobre los estudios curriculares son desafios que necesitan discutirse críticamente. Se incluye una breve referencia a las tradiciones curriculares y a los desafios metodológicos centrados en la investigación curricular, en Portugal. La lectura de este artículo adquiere gran importancia para los estudiantes de pregrado y posgrado, así como para profesores y educadores vinculados tanto a las cuestiones de la educación y la formación en general, como a los temas del plan de estudios, lo que incluye una referencia a la didáctica y la pedagogía.

Palabras clave: Estudios Curriculares. Teoría. Identidad. Investigación. Tradiciones 